\section{FUTEBOL, MÚSICA E LITERATURA: UMA ANÁLISE DOS HINOS DOS CLUBES ESPORTIVOS BRASILEIROS}

\section{Elcio Cornelsen}

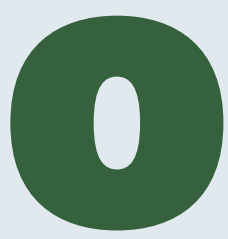

s encontros entre futebol, música e literatura ao longo do século XX no Brasil, sem dúvida, foram muito profícuos e contribuíram para a formação da identidade nacional da população em torno de suas maiores paixões, culminando com o que Nelson Rodrigues denominou emblematicamente de a "pátria em chuteiras" (1).

Como bem aponta o sociólogo português António da Silva Costa, "o futebol é uma das principais chaves de leitura de nossa sociedade. E tudo isso éfacilitado, sobretudo, pela natureza profundamente simbólica desse esporte e por seu funcionamento eminentemente ritualístico" (2). Justamente no que tange o seu caráter ritualístico, encontramos espaço para uma discussão transdisciplinar que envolve os âmbitos da literatura, da música e do futebol a partir do estudo de letras de hinos de clubes futebol.

Por definição, hino (do grego: v́ $\mu v o$ hymnos, "estrutura sonora”) é uma composição poético-musical de louvor ou exaltação. $\mathrm{O}$ hino é expressão de entusiasmo elevado, um poema ou cântico de veneração ou louvor à divindade e não segue, necessariamente, uma regularidade formal. Originalmente, era composto em ritmo livre e não tinha rima ou estrofação rígida. Além disso, o hino pode ser de espírito religioso, escrito especificamente para louvor ou adoração tipicamente endereçado a deuses e heróis (3). Esse sentido original, cujas raízes remontam à Antiguidade, se transformaria em séculos, até atingir o seu sentido na Modernidade, quando surgem, então, o hino nacional (de devoção à nação ou pátria), o hino partidário (de devoção a um partido político), o hino de organizaçôes em geral e o hino desportivo (de devoção a um clube ou agremiação) (4).

Desde 2009, quando iniciamos nossos estudos sobre as letras de hinos de clubes de futebol brasileiros, procuramos desenvolver um quadro de análise que nos possibilitasse avaliá-las em seus componentes líricos (a forma poética propriamente dita), épicos (elementos que alimentam o mito em relação à determinada agremiação, como alusão a símbolos, conquistas, virtudes etc) e dramáticos (as marcas textuais que denotam afetividade, apelo à fidelidade, emoção e louvor em relação ao clube) (5). Para isso, nos orientamos pela teoria dos gêneros literários proposta por Anatol Rosenfeld na década de 1960, ao considerá-los, justamente, de acordo com sua adjetivação, ou seja, como elementos épicos, líricos e dramáticos que podem estar presentes, simultaneamente, numa dada obra ou texto (6).

Há décadas, é lugar comum afirmar que "o futebol explica o Brasil” (7), numa alusão ao título da obra de Marcos Guterman, pu- blicada em 2009, ou mesmo quando o escritor José Lins do Rego, já na década de 1940, era categórico em afirmar que "o conhecimento do Brasil passa pelo futebol" (8). Sem dúvida, isso tem uma razão de ser, como bem aponta o sociólogo Roberto DaMatta ao considerar o futebol como "uma importante agência de dramatização da sociedade brasileira” (9).

Portanto, se o futebol é, por assim dizer, uma chave de leitura para a interpretação do Brasil, toda e qualquer manifestação cultural a ele associada se torna uma espécie de documento que certifica e reitera tal propriedade. É justamente dessa forma que lidamos em nosso estudo com as letras dos hinos de clubes de futebol brasileiros, pois entendemos que eles carregam em si várias informaçōes que não dizem respeito somente à história das próprias agremiações, mas também à história do país.

\section{OS HINOS DOS CLUBES DE FUTEBOL BRASILEIROS EM SEUS PRI-} MÓRDIOS É de conhecimento geral que o futebol, enquanto prática desportiva, chegou ao país no final do século XIX. Em seus primórdios, o football desfrutou de um significado "nobre", sobretudo porque era, majoritariamente, praticado em clubes seletos. Aqueles que, não obstante as controvérsias, são apontados por estudiosos como os pioneiros do futebol brasileiro Charles Miller, Hans Nobling, Oscar Cox, Victor Serpa, entre outros (10) - estudaram na Europa e conheceram no ambiente dos colleges britânicos ou suíços uma nova modalidade esportiva. Transplantado para a terra brasilis, levaria algum tempo até que o football criasse raízes profundas em nosso país, tornando-se o futebol, "the brazilian way of life" nas palavras do jornalista britânico Alex Bellos (11).

Portanto, em seus primórdios, a significação que se atribuiu ao football estava atrelada a um segmento minoritário da sociedade da época, pois, como nos lembra Roberto DaMatta, o futebol não tem em si um significado imanente e pode, desta forma, sofrer transformações em seu sentido, de acordo com os modos com que uma dada sociedade dele se apropria: o futebol é aquilo o que dele fazemos, pois, "como todas as atividades humanas, não teria uma essência que seria cheia ou vazia de consequências, mas dependeria da relação que estabelece com seus receptores num dado momento e numa dada sociedade" (12).

Como não poderia deixar de ser, isso se refletiu no modo como os clubes começaram a construir suas imagens identitárias enquanto pertencentes a esse ambiente elitizado. Tomemos, por exemplo, o primeiro hino oficial do Fluminense Sport Club, composto em 1915 pelo renomado escritor Coelho Neto, membro da cadeira $n^{\circ}$ 2 da Academia Brasileira de Letras (ABL) e autor de obras-primas como A conquista e Rei negro, e música baseada na canção "It's a long, long way to Tipperary", de H. Williams. A começar pelo primeiro verso que dá título ao hino, "O Fluminense é um crisol", já nota-se um estranhamento despertado pelo termo "crisol", totalmente em desuso nos nossos dias. Numa primeira tentativa de, literalmente, traduzi-lo, falaríamos de "cadinho", que, provavelmente, não diz muito para as gerações mais novas. Vejamos a seguir a letra do hino na íntegra: 
O Fluminense é um crisol Onde apuramos a energia Ao pleno ar, ao claro sol Lutando em justas de alegria O nosso esforço se congraça Em torno do ideal viril De avigorar a nova raça Do nosso Brasil!

Corrige o corpo como artista Vida imprime à estátua augusta Faz da argila uma robusta Peça de aço onde a alma assista $\mathrm{Na}$ arena como na vida Do forte é sempre a vitória Do estádio foi que a Grécia acometida Irrompeu para a glória

Ninguém no clube se pertence

A glória aqui não é pessoal

Quem vence em campo é o Fluminense

Que é, como a Pátria, um ser ideal

Assim nas justas se congraça

Em torno dum ideal viril

A gente moça, a nova raça

Do nosso Brasil! (13)

Nota-se, de antemão, uma estrutura formal rígida, à moda de um poema parnasiano, em voga na época, própria para um hino de caráter marcial. Como forma e conteúdo estão intimamente ligados, o vocabulário empregado também reflete esse caráter. Sem dúvida, o processo de enobrecimento do football — e do Fluminense - é patente nos versos de Coelho Neto, as referências espaciais procuram unir o Brasil à Grécia antiga, em que o clube emerge como um celeiro para forjar — o termo é apropriado a "crisol" — uma "nova raça", pois "Corrige o corpo como artista/Vida imprime à estátua augusta”, numa alusão à iconografia no âmbito dos esportes, marcadamente em sua origem pelas artes plásticas na Antiguidade.

Além disso, os versos "Do estádio foi que a Grécia acometida/ irrompeu para a glória”, hoje em dia, nos soam demasiadamente estranhos como partes integrantes da letra de um clube de futebol. Poderíamos nos indagar: o que levou Coelho Neto a essa associação? E neste ponto começamos a compreender que a máxima "o futebol explica o Brasil" não é tão infundada assim. Para o "nobre esporte bretão" das primeiras décadas do século XX, era importante assegurar-lhe um "pedigree" à altura daqueles que o cultuavam - dentro e fora do field —, e nada mais natural que revesti-lo de um caráter "olímpico", que sempre desfrutou de um sentido positivo na civilização ocidental, ainda mais numa época em que o Movimento Olímpico Internacional se consolidava através dos esforços de Pierre de Coubertin. Cabe ressaltar também que, dentro desse procedimento, as virtudes são amplamente enaltecidas na letra de Coelho Neto: energia, combatividade, vigor, virilidade, força, alegria, mocidade, glória.
De acordo com a jornalista Cláudia Mattos (14), a letra de Coelho Neto apresentava aspectos que refletiam certa postura elitista e racista quanto à sociedade brasileira da época. De origem nobre, um "clube de ingleses", a "nova raça" do Brasil, apregoada na letra, não se referiria à miscigenação, mas sim às origens elitistas do clube, que não aceitava jogadores negros em suas fileiras, nas duas primeiras décadas do século XX. Sem dúvida, esse foi um fator que influenciou na decisão de se compor um novo hino oficial para o Fluminense no início da década de 1920, levado a cabo por Antônio Cardozo Menezes Filho.

Sem dúvida, hinos como esse, de caráter marcial, carregam consigo marcas - textuais — de um tempo em que o football ainda não tinha se popularizado e se tornado o futebol. E se levarmos em conta o argumento de Cláudia Mattos, de que, nas primeiras décadas de sua existência, o ingresso de negros no clube era interditado, somos levados a deduzir também algumas peculiaridades da sociedade brasileira à época. Mesmo que o seguinte quadro soe demasiado genérico, parece-nos que ele não está tão longe da realidade: para se popularizar, o football — ainda na fase do amadorismo - teve de perder o seu "pedigree", teve de deixar de ser um objeto da society elitizada, teve de sair do field para atingir as margens dos centros urbanos brasileiros que cresciam à época, teve de ir para os terrenos baldios, campos improvisados e várzeas modestas. Neste ponto, a década de 1920 é decisiva, pois não só haverá uma maior integração de jogadores negros nas agremiações, com destaque para o Clube de Regatas Vasco da Gama (15), como também começa a se estabelecer a profissionalização dos jogadores de futebol, até ser oficializada em 1933.

O que nos motivou a eleger a letra do primeiro hino oficial do Fluminense como exemplo de uma época em que o futebol ainda não havia se popularizado foi a possibilidade de poder aludir a essas questôes de ordem sociocultural e histórica. A própria sociedade brasileira se reestruturava após a promulgação da Lei Áurea em 1888 e, respectivamente, a Proclamação da República em 1889. Se levarmos em conta que Coelho Neto compôs a letra em 1915, faziam menos de 30 anos que esses acontecimentos históricos haviam ocorrido. A Lei Áurea não teve força para impedir que o preconceito no Brasil grassasse naquelas primeiras décadas e que chegasse até nossos dias. $\mathrm{E}$ a estratificação social pós-lei lançou milhōes, simbólica e fisicamente, à margem. E quando pensamos em aspectos como esses associados ao futebol, não podemos deixar de reconhecer o seu valor para a cultura brasileira. Isso, aliás, nos faz lembrar Oswald de Andrade e o Manifesto Antropófago de 1928: o produto final do football foi o futebol num processo de democratização cultural no Brasil.

\section{OS HINOS DE CLUBES DE FUTEBOL BRASILEIROS NA ERA DE SUA PO-} PULARIZAÇÃO Ao contrário dos hinos marciais das décadas de 1910 e 1920, os hinos que surgiram a partir da década de 1930 no Brasil acompanharam o processo de popularização do futebol, afastandose, assim, cada vez mais, de um sentido marcial e discursivamente "enobrecido" que, por exemplo, remontasse ao berço dos esportes na Grécia antiga. Ao contrário, os chamados hinos populares, em sua imensa maioria, desde o início refletiram em sua composição o espaço que o futebol atingira em nossa cultura. Decisivo nesse processo 
foi a aliança do futebol com a música, mais especificamente o samba, outra manifestação de caráter popular que havia se consolidado no mesmo período. Mas é com o Carnaval e, mais especificamente, com o seu ritmo mais marcante, a marcha-rancho ou "marchinha", como é popularmente conhecida, que o futebol encontraria a sua trilha sonora apta a lhe atribuir traços de identidade.

Certo conhecimento que temos a respeito de composições de hinos de clubes esportivos em outros países, como em Portugal e na Alemanha, nos permite afirmar que, nesses países, os hinos também receberam traços daqueles ritmos considerados populares, como o fado no caso português, ou como as chamadas "cançôes de cervejaria”, no caso alemão, estas mantendo ainda alguns traços rítmicos que aludiam ao compasso dos antigos hinos marciais, fundamentalmente executadas ao som de metais e instrumentos de sopro. Portanto, o mesmo fenômeno cultural ocorrido no Brasil, quando falamos de hinos de futebol, também ocorreu em outros países, mas o diferencial está, justamente, no tipo de ritmo popular que permitiu esse casamento entre música e futebol.

Em estudo publicado sobre a visceral relação entre música e futebol no Brasil, o jornalista Beto Xavier aponta para o fato de que, embora o futebol já fizesse parte da vida dos músicos brasileiros no início do século XX, foi somente no final da década de 1920 que o encontro entre música e futebol "ganharia seu primeiro grande registro" (16), mais precisamente com o choro " 1 x 0 ", de autoria de Pixinguinha e Benedito Lacerda, num momento áureo da chamada "era do rádio". Outros se seguiriam nas décadas posteriores e se tornariam verdadeiros clássicos do gênero, como os choros "A ginga do Mané”, de Jacob do Bandolim, "Radamés y Pelé”, de Tom Jobim, e "Esquerdinha na gafieira", de Altamiro Carrilho (17). Porém, estes permaneciam ainda no âmbito da música instrumental, sem integrar o texto poético.

Mas é, sobretudo, com a criação de hinos de futebol que esse encontro entre música e futebol se amplia, integrando a literatura, mais especificamente a arte poética. Pois o hino é uma criação mista e, como tal, marcada pela inclusão simultânea do elemento musical e do verbal, como ressalta Solange Ribeiro de Oliveira (18).

Não é por acaso que música e futebol se aliarão ao longo do século XX no Brasil, em parcerias muito felizes, envolvendo nomes como Ary Barroso, Lamartine Babo, Wilson Batista, Lupicínio Rodrigues, Tom Zé, Gonzaguinha, João Bosco, Jorge Ben Jor, Paulinho Nogueira, Aldir Blanc, Chico Buarque, e tantos outros, verdadeiros mestres em exaltar a paixão nacional. E a elas se juntará a literatura, seja em romances, contos, poesias e crônicas, através de escritores como Carlos Drummond de Andrade, José Lins do Rego, Nelson Rodrigues, Paulo Mendes Campos, João Cabral de Melo Neto, Alcântara Machado, Vinícius de Moraes, Carlos Heitor Cony, Edilberto Coutinho, Luis Fernando Veríssimo, Moacyr Scliar, Roberto Drummond, entre outros.

Por sua vez, podemos afirmar com segurança que a transição dos chamados hinos marciais para os hinos populares no âmbito do futebol se consolidou em meados da década de 1940. Sem dúvida tal transição está associada a Lamartine Babo (1904-1963), famoso compositor de marchas de carnaval que compôs nada mais nada menos do que os hinos de 11 clubes do Rio de Janeiro: América, time de coração do compositor, Botafogo, Flamengo, Fluminense, Vasco da Gama, Bangu, todos considerados "grandes” na época, e dos times "modestos" Madureira, Olaria, São Cristóvão, Bonsucesso e Canto do Rio (19).

Segundo consta, "Lalá", como Lamartine era conhecido, foi desafiado pelo radialista Héber de Bôscoli, com quem compunha o "Trio de osso" juntamente com Yara Sales no programa Trem da Alegria, da Rádio Mayrink Veiga, a compor um hino por semana para cada clube do Rio de Janeiro, desafio esse plenamente cumprido pelo compositor (20). Aliás, Lamartine Babo faria escola também quanto ao estilo dos hinos de futebol, compostos como marchas-rancho, e estas se diferenciavam das marchas militares em sua cadência. Ao se referir a essa associação entre futebol e carnaval, Paulo Jebaili afirma que "[o] hino de futebol escolhe a marcha porque é a festa. E a festa é sublimação da dor. A marcha é uma das primeiras manifestações de pessoas que se reuniam em blocos na rua para cantar a vida de forma lúdica” (21).

Para ilustrarmos o tipo de hino composto na fase de consolidação do futebol como fenômeno cultural popular, elegemos, mais uma vez, o Fluminense Football Club e seu terceiro hino da história, composto na década de 1940, com letra de Lamartine Babo e música do maestro Lyrio Pannicalli, que vai à contramão dos hinos anteriores, uma vez que rompe com a tradição marcial, assumindo um caráter eminentemente popular. Nossa escolha por esse hino não se deve apenas ao fato de que, metodologicamente, se torna mais interessante em termos de ilustração ao ser contraposto ao hino composto por Coelho Neto em 1915, mas, sobretudo, pelo fato de ser um dos mais belos hinos compostos para clubes do futebol brasileiro:

Primeiramente, podemos constatar que, em termos formais, a letra apresenta variação, portanto, sem a mesma rigidez da letra do primeiro hino oficial. Em segundo lugar, por se tratar de uma letra de caráter popular, certos elementos épicos se fazem presentes com toda sua força, a começar pelo modo como se constrói a cena narrativa, em que um "eu" se insere, aspecto totalmente ausente nos hinos marciais, quando predomina o sujeito coletivo "nós": "Sou tricolor de coração / Sou do clube tantas vezes campeão" / "Eu sou é tricolor”.

Além disso, a letra inclui feitos heroicos e conquistas, outro traço ausente em hinos marciais, eminentemente atemporais: "Retumbante de glórias / E vitórias mil" / "Faz a torcida querida / Vibrar de emoção o tricampeão", sendo que este último verso refere-se à conquista dos títulos de campeão carioca dos anos de 1917, 1918 e 1919. Já o modo como o clube é situado em termos de espaço, enquanto marca textual, refere-se ao âmbito nacional no verso "Clube que orgulha o Brasil”, e a identidade simbólica é amplamente explorada, sobretudo com relação às cores do tricolor — verde, vermelho e branco: "Salve o querido pavilhão / Das três cores que traduzem tradição" / "Com o verde da esperança” / "Com o sangue encarnado" / "Branco é a paz e harmonia" / "Salve o tricolor".

Por sua vez, os aspectos dramáticos também são bem marcados na letra composta por Lamartine Babo, algo que, pelo caráter "viril" dos hinos marciais, ou mesmo pelo investimento num sujeito coletivo "nós" como representante daquele sentimento que Hilário Franco Júnior chamou de "espírito clânico" (23), não figurava nas 
letras de hinos compostas nos primórdios do futebol brasileiro. Ao contrário, por seu caráter popular, há espaço na letra do hino popular para a afetividade — "Sou tricolor de coração" / "Eu tenho amor ao tricolor" —, a emoção — "Fascina pela sua disciplina / O Fluminense me domina" / "Faz a torcida querida / Vibrar de emoção o tricampeão" —, o apelo à fidelidade — "Sou tricolor de coração"; "Eu sou é tricolor" — e o louvor — "Salve o querido pavilhão"; "Salve o tricolor".

Sou tricolor de coração

Sou do clube tantas vezes campeão

Fascina pela sua disciplina

O Fluminense me domina

Eu tenho amor ao tricolor

Salve o querido pavilhão

Das três cores que traduzem tradição

A paz, a esperança e o vigor

Unido e forte pelo esporte

Eu sou é tricolor

Vence o Fluminense

Com o verde da esperança

Pois quem espera sempre alcança

Clube que orgulha o Brasil

Retumbante de glórias

E vitórias mil

Vence o Fluminense

Com o sangue do encarnado

Com calor e com vigor

Faz a torcida querida

Vibrar de emoção o tricampeão

Sou tricolor de coração

Sou do clube tantas vezes campeão

Fascina pela sua disciplina

O Fluminense me domina

Eu tenho amor ao tricolor

Salve o querido pavilhão

Das três cores que traduzem tradição

A paz, a esperança e o vigor

Unido e forte pelo esporte

Eu sou é tricolor

Vence o Fluminense

Usando a fidalguia

Branco é paz e harmonia

Brilha com o sol

Da manhã

Com a luz de um refletor

salve o tricolor. (22)
Portanto, podemos afirmar que o hino popular composto por Lamartine Babo e, desde então, executado nos momentos de festividade e de conquistas do Fluminense suplanta os hinos anteriores - tanto o de Coelho Neto, quanto o de Cardozo de Menezes Filho, este último não abordado no espaço deste estudo. Lamartine Babo, que nem era tricolor, mas sim torcedor fanático do América do Rio, teve a sensibilidade para compor um texto que muito nos diz em termos do modo de cantar os feitos de um clube com alegria e, sobretudo, tolerância.

OUTROS HINOS POPULARES DE CLUBES DO FUTEBOL BRASILEIRO: ALGUMAS CURIOSIDADES ANTES DO APITO FINAL O estudo de letras de hinos de clubes de futebol brasileiro nos possibilita percorrer uma via de mão dupla: se num sentido podemos analisar o modo como as imagens dos clubes são construídas, noutro, podemos refletir também sobre o contexto sócio-histórico em que foram compostas, numa leitura chave para a própria sociedade brasileira.

Nesse sentido, são inúmeras as curiosidades reveladas por um estudo dessa natureza. Basta pensarmos, por exemplo, na letra do hino do Grêmio Foot-Ball Porto Alegrense, composta pelo sambista Lupicínio Rodrigues em 1954, que viria a substituir o primeiro hino oficial do clube, composto em 1924 por Isolino Leal, de caráter marcial, e o segundo hino, de 1946, "Marcha de guerra do Grêmio Porto Alegrense", composto por Breno Blauth. Tomemos os versos que compõem o refrão: "Até a pé nós iremos / Para o que der e vier / Mas o certo é que nós estaremos / Com o Grêmio, onde o Grêmio estiver". Apenas esses versos já dão margem para algumas conjecturas, entre elas, o sujeito coletivo "nós" do "espírito clânico" enquanto componente épico, apontado anteriormente, e também uma marca de apelo à fidelidade, de caráter dramático. Tais versos cantam o esforço do torcedor gremista em acompanhar o clube onde quer que ele vá ou esteja, mesmo que isso possa significar um tremendo esforço de ir a pé. Reza a lenda, entretanto, que esses versos tiveram uma motivação bem concreta, por ocasiāo de uma greve de condutores de bondes na capital gaúcha, em 1953, ano do cinquentenário do clube, que comprometera até mesmo a realização de jogos na cidade. Naquela oportunidade, Lupicínio teria se sentado numa mesa de bar e composto os famosos versos. Entretanto, nem tudo foi inspiração do poeta boêmio, pois se valeu de uma frase que torcedores do Grêmio exibiam estampada numa faixa, nos jogos da equipe: "Com o Grêmio onde estiver o Grêmio”, frase atribuída a Salim Nigri (24).

Na letra do hino popular do Grêmio, temos, portanto, um título exemplo de intertextualidade entre a frase da faixa e os versos de $\mathrm{Lu}$ picínio Rodrigues. Aliás, a intertextualidade pode ocorrer também entre hinos. Bons exemplos disso são as letras dos hinos compostos por Lamartine Babo. Os versos do hino do Clube de Regatas Flamengo, composto por Lalá, enfatizam o apelo à fidelidade, um dos elementos dramáticos presentes em letras de hinos populares de clubes de futebol: "Vencer, vencer, vencer / Uma vez Flamengo, / Flamengo até morrer" (25). Algo semelhante ocorre com os versos do hino do América do Rio: "Hei de torcer, torcer, torcer / Hei de torcer até morrer, morrer, morrer" (26). Além do apelo à fidelidade 
“até morrer”, há também um traço estilístico de Lamartine ao empregar os verbos "vencer", "torcer" e "morrer" em repetição trina.

Lamartine, por assim dizer, faria escola, pois décadas mais tarde, outro compositor de marchinhas de carnaval em Minas Gerais, Vicente Motta, se inspiraria naqueles hinos para compor a letra do hino do Clube Atlético Mineiro, em 1969, conforme demonstram os seguintes versos:

\section{$[\ldots]$}

Vencer, vencer, vencer...

Este é o nosso ideal.

[...]

Lutar, lutar, lutar...

Pelos gramados do mundo para vencer.

Clube Atlético Mineiro,

Uma vez até morrer.

Lutar, lutar, lutar...

Com toda a nossa raça pra vencer.

Clube Atlético Mineiro,

Uma vez até morrer (27).

Consta ainda que, prestigiado por ter vencido as últimas duas edições de concursos de marchinhas de carnaval na cidade de Belo Horizonte, Vicente Motta, que compôs também o hino do América mineiro, foi contratado pela diretoria do Atlético com a incumbência de exaltar a excursão vitoriosa à Europa, empreendida pelo clube em 1950, e também o título de Campeão dos Campeões de 1937. Tais feitos estão registrados nos versos "Nós somos campeōes do gelo / O nosso time é imortal / Nós somos campeões dos campeões / Somos o orgulho do esporte nacional" (27).

Outra peculiaridade desse hino, que também se tornaria recorrente em outros hinos mais recentes, é a referência à mascote do clube: "Clube Atlético Mineiro / Galo Forte Vingador". Cabe lembrar que a criação de mascotes para os clubes se deu, sobretudo, nas décadas de 1930, 1940 e 1950, no bojo da popularização do futebol. E muito mais curiosidades podem ser reveladas por um estudo dessa natureza, que nos auxiliam a "ler" o Brasil através do futebol.

Trila o apito final.

Elcio Cornelsen é professor associado da Faculdade de Letras da Universidade Federal de Minas Gerais (UFMG) que atua nos programas de pós-graduação em estudos literários dessa instituição e no interdisciplinar em estudos do lazer, da Escola de Educação Física, Fisioterapia e Terapia Ocupacional. Desde 2010, coordena o Núcleo de Estudos sobre Futebol, Linguagem e Artes (Fulia), éébolsista de produtividade em pesquisa do CNPq e do Programa Pesquisador Mineiro da Fapemig.

\section{NOTAS E REFERÊNCIAS BIBLIOGRÁFICAS}

1. Rodrigues, N. "A pátria em chuteiras". In: Rodrigues, N. A pátria em chuteiras: novas crônicas de futebol. São Paulo: Companhia das Letras. 1994. pp 179-181.

2. Costa, A. da S. "Apresentação". In: Lovisaro, M.; Neves, L. C. (org.).
Futebol e sociedade: um olhar transdisciplinar. Rio de Janeiro: Ed. Uerj. 2006. p 9.

3. Bilac, O.; Passos, G. Tratado de versificação. 6. ed., São Paulo; Rio de Janeiro: Francisco Alves. 1930. p 110.

4. Cornelsen, E. "Literatura, música e futebol: um olhar transdisciplinar". In: Holanda, S. A. de O. (et al.) (org.). Amazônia, culturas, linguagens. Curitiba: Ed. CRV. 2011. pp 134-135.

5. Cornelsen, E. "Hinos de futebol nas Gerais: dos hinos marciais aos populares". Aletria. n. 2, v. 22, pp 60-61, maio-ago. 2012.

6. Rosenfeld, A. O teatro épico. São Paulo: Desa. 1965. pp 3-26.

7. Guterman, M. O futebol explica o Brasil: uma história da maior expressão popular do país. São Paulo: Contexto. 2009.

8. In: Língua Portuguesa. caderno especial Futebol \& Linguagem. ano I, p 66, abril de 2006.

9. DaMatta, R. "Antropologia do óbvio: um ensaio em torno do significado social do futebol brasileiro". In: DaMatta, R. A bola corre mais que os homens. Rio de Janeiro: Rocco. 2006. p 163.

10. Couto, E. de F. "Os primórdios do futebol em Belo Horizonte. Aspectos do pertencimento clubístico (1908-1927)". In: Silva, S. R. da; Debortoli, J. A. de O.; Silva, T. F. da (org.). O futebol nas Gerais. Belo Horizonte: Ed. UFMG. 2012. p 113.

11. Bellos, A. Futebol: the Brazilian way of life. London:Bloomsbury. 2002.

12. DaMatta, R. "Os milagres do futebol". In: DaMatta, R. Explorações: ensaios de sociologia interpretativa. 2. ed., Rio de Janeiro: Rocco. 2011. p 88-89.

13. Netto, C. "Primeiro hino oficial do Fluminense Football Club (1915)". Disponível em: http://www.fluminense.com.br/index.php?option=com content\&view=article\&id=83\&ltemid=83; acesso em: 05 ago. 2009.

14. Mattos, C. "Fluminense e a origem nobre". In: Mattos, C. Cem anos de paixão: uma mitologia carioca no futebol. Rio de Janeiro: Rocco. 1997. p 54-56.

15. Franzini, F. "Quando a bola tinha cor". In: Franzini, F. Corações na ponta da chuteira: episódios iniciais da história do futebol brasileiro (19191938). Rio de Janeiro: DP\&A. 2003. pp 46-47.

16. Xavier, B. Futebol no país da música. São Paulo: Panda Books. 2009. p 25.

17. Xavier, B., op.cit. p 37.

18. Oliveira, S. R. de. Literatura e música: modulações pós-coloniais. São Paulo: Perspectiva. 2002. p 12.

19. Xavier, B., op. cit., p 52.

20. Valença, S. Tra-la-lá. Rio de Janeiro: Funarte. 1981. p 158.

21. Jebaili, P. "Para cantar de cor". Língua Portuguesa. caderno especial Futebol \& Linguagem. ano I, p 55, abril de 2006.

22. Babo, L.; Pannicalli, L. "Hino popular do Fluminense Sport Club (1945)". Disponível em: http://www.fluminense.com.br/index. php?option=com content $\& v i e w=a r t i c l e \& i d=83 \&$ ltemid=83; acesso em: 05 ago. 2009.

23. Franco Junior, H. A dança dos deuses: futebol, cultura, sociedade. São Paulo: Companhia das Letras. 2007. pp 213-224.

24. Xavier, B., op. cit., p 121.

25. Valença, op. cit., p 159.

26. Valença, op. cit., p 160.

27. Motta, V. Hino atual do Clube Atlético Mineiro (1969). Disponível em: http://www.atletico.com.br/site/cam/hino; acesso em: 05 ago. 2009. 